\title{
REPENSAR A VISÃO CRIACIONISTA: cristianismo e ecologia
}

\author{
Rethinking the creationism: \\ christianity and ecology
}

\section{José Roque Junges}

Padre, Professor Doutor em Teologia Moral pela Pontificia Università Gregoriana de Roma, Itália, Professor de bioética nos cursos de graduação da área de saúde e professor/pesquisador do PPG em Saúde Coletiva da Universidade do Vale do Rio dos Sinos (UNISINOS), São Leopoldo, RS - Brasil, e-mail: roquejunges@hotmail.com

\section{Resumo}

A crise ambiental obriga os cristãos a repensar a visão tradicional da criação, porque vários ecologistas responsabilizam essa visão pela destruição do meio ambiente. Compreender a criação a partir da teoria do jogo pode ser um caminho epistemológico para esse repensar. A doutrina tradicional da criação assumiu, para explicação da origem do mundo, a forma calculista e controladora da ciência moderna. Essa é a causa do conflito entre criacionistas e evolucionistas. O modelo do jogo introduz o risco, a inventividade e a imprevisibilidade na criação, abrindo espaço para a liberdade e a graça. Significa pensar o ato de criar no contexto relacional, permitindo resgatar a ação da Trindade como nova criação e, principalmente, 
a visão de uma criação contínua. Abre também perspectivas para reconsiderar a compreensão sobre o papel do ser humano na criação e redescobrir o sentido ecológico do descanso sabático. A teologia da criação, proposta por Moltmann, é um modelo adequado para essa revisão.

Palavras-chave: Crise ambiental. Cristianismo. Criação. Ecologia. Teoria do Jogo.

\section{Abstract}

The environmental crisis obliges the Christians to rethink about the traditional creation's vision, because several ecologists say that this vision is responsible for the environmental destruction. Understanding the creation by the game theory could be an epistemological way to this rethinking. The traditional doctrine of creation took, for the explanation of the origin of the world, the calculating and controlling form of the modern science. This is the cause of the conflict between creationism and evolutionism. The model of the game introduces risk, inventiveness and unexpectedness in the creation, opening space for liberty and grace. This means thinking the act of create in a relational context, allowing recovering the action of the Trinity as new creation and, mainly, the vision of a continuous creation. It also opens also perspectives to reconsider the comprehension about the role of the human being in creation and rediscovering the ecological sense of the sabbatical repose. Theology of Creation, proposed by Moltmann, is the appropriate model for this revision.

Keywords: Environmental crisis. Christianity. Creation. Ecology. Game Theory.

\section{Introdução}

O aquecimento global acirrou a consciência ecológica em relação às consequências ameaçadoras das intervenções humanas para o meio ambiente. Fez a humanidade dar-se conta de que a solução não depende apenas de inovações tecnológicas, mas de um novo paradigma cultural no modo de relacionar-se com a natureza. Os cristãos são convidados a perguntar-se em que podem ajudar para essa nova consciência, para que as respostas não sejam cosméticas, mas pautadas por uma ecologia profunda.

Rev. Pistis Prax., Teol. Pastor., Curitiba, v. 1, n. 2, p. 355-369, jul./dez. 2009 


\section{Os cristãos e a crise ecológica}

Ao emergir a consciência da crise ambiental e a respectiva busca das suas causas em vista de uma resposta adequada, alguns autores, interessados na questão ecológica, acusaram o Cristianismo como responsável cultural do desrespeito pela natureza. Um artigo do historiador americano Lynn White (1967) da Universidade da Califórnia deu origem a essa acusação e tornou-se clássico em sua interpretação. Para ele, a crise ecológica tem um fundo religioso e a sua solução passa pela religião. Por isso, defende a necessidade de uma crítica do Cristianismo ocidental, responsável dentro do cenário das religiões, pela desmistificação da natureza e a introdução de um antropocentrismo extremado. Os problemas ecológicos exigem uma mudança na perspectiva religiosa: uma visão remistificada da natureza e uma atitude mais biocêntrica.

Para White (1967), o Judaísmo e o Cristianismo introduziram uma concepção linear e finalizada do tempo, ao contrário das religiões naturais que têm uma maneira repetitiva e cíclica de encarar o tempo. Para as primeiras, o mundo teve um início e terá um fim. Deus criou tudo, no tempo inicial, fazendo existir e sustentando todas as coisas na sua existência e encaminhando-as para um fim escatológico. Para uma visão cíclica é impossível falar de um início e de um fim. O mundo não teve começo, mantendo-se pela contínua repetição dos ciclos naturais. A concepção linear possibilita a ideia de progresso que é inconcebível numa visão cíclica do tempo, muito mais respeitadora do meio ambiente, porque leva em conta a dinâmica repetitiva dos ciclos da natureza.

White (1967) sustenta também que, para as religiões naturais, lugares, animais e plantas têm seus espíritos, porque tudo é animado. Para intervir na natureza é necessário consultar os espíritos e oferecer sacrifícios a eles. Para derrubar uma árvore ou caçar um animal deve-se pedir licença ao respectivo espírito da floresta ou do reino animal. Para explorar uma mina, consultar o espírito da montanha. O Cristianismo combateu este animismo pagão, esvaziando a natureza de seus espíritos protetores e abrindo a possibilidade a uma exploração indiferente à sensibilidade dos seres naturais. No lugar desses espíritos, o Cristianismo ofereceu os santos. Mas essa substituição écompletamente diferente do animismo, pois o santo não éum ser natural. Trata-se de um ser humano que habita os céus e não a natureza. Os próprios anjos e demônios não habitam a natureza e estão relacionados com o ser humano. Os espíritos das montanhas, dos rios, das florestas, dos animais que protegiam a natureza da depredação do ser humano evaporaram por obra da pregação cristã.

Rev. Pistis Prax., Teol. Pastor., Curitiba, v. 1, n. 2, p. 355-369, jul./dez. 2009 
A principal causa da crise ecológica, segundo White (1967), é uma visão centrada na humanidade. Para as religiões animistas, o ser humano está inserido na natureza como um ser a mais, ao lado de outros, sem ocupar uma posição de proeminência. Para a visão cristã, o ser humano foi criado à imagem e semelhança de Deus, ocupando um lugar de destaque e recebendo um encargo especial em relação à criação. Essa concepção origina uma perspectiva antropocêntrica que distancia o ser humano dos restantes seres naturais. Ele se sente sujeito diante de uma natureza objeto. Esse antropocentrismo abriu as portas para a exploração da natureza em proveito dos interesses humanos.

O domínio da natureza pelo saber científico e tecnológico completa como consequência lógica os outros aspectos característicos do Cristianismo. O “crescei e multiplicai-vos e dominai a terra” de Gn 1,28 expressa, segundo White (1967), a vontade explícita de Deus de que o ser humano explore a natureza para os seus fins. Subjugue suas forças e liberte-se de seu determinismo pelo engenho da sua inteligência. Neste submeter a natureza, o ser humano expressa sua imagem e semelhança divina. Assim, a fé cristã é responsabilizada pela origem e a forma assumida pela ciência e a técnica no mundo moderno. A civilização científico-tecnológica moderna só seria possível dentro do Cristianismo ocidental. White (1967) reconhece que existiram outras tradições cristãs que se posicionaram diferentemente diante da natureza, mas que não conseguiram impor-se e permaneceram minoritárias, como o cristianismo oriental grego e o movimento e figura de Francisco de Assis.

O que dizer dessa análise crítica de Lynn White?

Ele aponta para aspectos característicos da visão criacionista do Judaísmo e Cristianismo: a concepção não cíclica do tempo; a natureza considerada como criada por Deus, não povoada de forças e espíritos ameaçadores; o ser humano concebido à imagem divina, como guardião encarregado de cuidar da natureza por incumbência do Criador. Mas apontar essas características como responsáveis pela crise ambiental é um simplismo que desconhece a complexidade dos contextos culturais (MONCRIEF, 1970).

As causas da crise ecológica devem ser buscadas na história de efeitos da modernidade: o individualismo e a autonomia, introduzidas pela revolução francesa, e o uso das inovações tecnológicas protagonizada pela revolução industrial. A conjunção do capitalismo com a democracia possibilitou o surgimento da industrialização e da urbanização, o crescimento da riqueza e da 
população, a apropriação privada dos recursos e a exploração dos recursos naturais. Esses elementos estão presentes também em países que não são de tradição cristã. Eles são os verdadeiros causadores da degradação ambiental.

A visão criacionista cristã pode ser um fator indireto para o surgimento da ciência e da tecnologia pela maneira de conceber a natureza, mas não pode ser responsabilizada pela forma concreta em que elas se desenvolveram e principalmente pelo uso predatório da natureza. A ciência e a tecnologia foram colocadas a serviço da industrialização impulsionada pelo liberalismo e capitalismo. Esse é o verdadeiro contexto cultural da atual crise ecológica. Essas ideologias podem ter usado elementos da visão criacionista cristã para justificar sua prática dominadora em relação à natureza. Por isso, é necessário assumir o desafio de repensar a doutrina cristã da criação num contexto ecológico, descodificando criticamente certas interpretações e dando um sentido aos textos bíblicos que seja significativo para a compreensão dos desafios atuais do respeito à natureza.

Mas para realizar essa reinterpretação é necessário assumir epistemologicamente a perspectiva do jogo, proposta por Euvé (2006), como metáfora para entender o mundo e a criação. Essa visão permite reintroduzir teologicamente a compreensão trinitária da criação, entendida como nova criação e criação contínua como aparece na compreensão de Moltmann (1993) sobre a criação.

\section{Criação como jogo}

Introduzir o jogo para compreender o mundo significa contrapor a atitude lúdica do risco e da imprevisibilidade do resultado à atitude científica do cálculo e do controle. Significa completar o discurso sistemático da ciência sobre o mundo com a surpresa e inventividade em relação às regras, típica de qualquer jogo. A doutrina cristã da criação assumiu para explicação da origem do mundo, a forma calculista e controladora da ciência moderna. Essa perspectiva epistemológica está na origem dos problemas em relação à explicação criacionista e, certamente, é a causa do conflito com os evolucionistas. Adotar o conceito de jogo na teologia da criação (EUVÉ 2006) tem uma função metafórica de quebra de paradigma. Para Ricoeur (1975, p. 369), com a metáfora, rompe-se uma interpretação inadequada de uma situação em proveito de uma interpretação nova, mais adequada.

Rev. Pistis Prax., Teol. Pastor., Curitiba, v. 1, n. 2, p. 355-369, jul./dez. 2009 
JUNGES, J. R.

O jogo é uma noção aberta, suscetível de deslocar ênfases, de assumir fluidez e dinâmica contra o desgaste inerente a toda representação. Jogar é entabular relações. O jogo requer parceiros. A noção de jogo só adquire sentido em confronto com outros. O jogo necessita regras, mas não existe jogo sem inventividade, indo além das regras. A pura execução das regras não é jogo. O modelo lúdico permite compreender melhor a dinâmica entre liberdade e regra. O jogo não permite a previsão do resultado. A imprevisibilidade e o risco fazem parte do jogo. O mundo lúdico quebra o esquema de controle e de cálculo típico da vida cotidiana. Por fim uma das principais características do jogo é a alegria e a gratuidade. O jogo não faz parte do mundo da utilidade. Joga-se justamente para descansar, dedicando-se ao que é gratuito para além dos critérios exigentes do utilitário (EUVÉ, 2006).

Esse modelo lúdico fornece melhores elementos para a compreensão bíblica da criação. A Literatura Sapiencial da Bíblia e posteriormente a Teologia Patrística assumiram essa perspectiva. Assumir esse modelo significa pensar a criação num contexto relacional, antes de nada, pela ação criadora da relação entre as três pessoas da Trindade, mas também porque criar é entabular uma relação e constituir um interlocutor no diálogo, já que Deus cria por amor e não por necessidade. Entender o ato divino de criar como jogar significa assumir a inventividade dos seres criados que não simplesmente executam as regras e a imprevisibilidade do resultado, o risco de não expressar o previsto, tendo a liberdade de se reinventar. Esse é o fundamento da contingência da criatura e a origem da possibilidade do mal. Essa criação não movida pela dinâmica da necessidade, mas da liberdade, explica-se porque Deus cria na gratuidade e por amor.

Associar o jogo à criação é, consequentemente, reafirmar que Deus 'cria por prazer', que encontra sua alegria criando o mundo, e a transmite às suas criaturas. Em decorrência, significa dizer que a criação é, para quem a contempla com a simplicidade do olhar de criança, fonte de maravilhamento e de louvor. Em face da austera severidade das construções da técnica, o cosmo reencontra o encantamento primordial. A dimensão festiva está presente aqui e agora, sem esperar o fim dos tempos, porque a criação já é agora boa e fonte de alegria. (EUVÉ, 2006, p. 284).

Rev. Pistis Prax., Teol. Pastor., Curitiba, v. 1, n. 2, p. 355-369, jul./dez. 2009 


\section{Trindade e criação}

O teólogo Juan Vives (1990, p. 52) afirma, com muito acerto, de que:

Só se alcança uma correta concepção da criação a partir da revelação da Trindade. Isso é assim, porque falar de um Deus criador é falar de um Deus pessoal, não de um princípio metafísico ou de uma causa física que atua por necessidade; é falar de um Deus livre e autocomunicativo que é palavra de amor. Este Deus só pode ser o Deus trinitário da revelação.

Somente assumindo essa perspectiva trinitária pode-se compreender a criação contínua e a nova criação.

O esquecimento da Trindade foi motivado por uma compreensão mais filosófica do que bíblica de Deus. A teologia escolástica fazia uma distinção indevida entre "Deus Uno” em sua essência (De Deo Uno) e "Deus trino" nas pessoas (De Deo Trino). Deus era explicado a partir de sua essência, responsável pela unidade, e depois se via como conjugar essa unidade com as pessoas. Ao primeiro era devida a criação e ao segundo, a salvação. Assim, a criação era obra da essência divina em que não participava a Trindade. Nesta perspectiva, a encarnação do Verbo tinha a ver com a caída do pecado e a salvação e não com a criação. Ao contrário, é imperioso afirmar que a criação não tem tanto a ver com a natureza divina, mas com as pessoas da Trindade. Elas são o próprio fundamento da criação.

A criação é uma autocomunicação amorosa de ser, de bem e de vida que já acontece dentro da própria Trindade. Só um Deus pessoal pode criar, porque faz emergir um outro para se autocomunicar. Do contrário, a criação é apenas uma emanação de Deus (emanantismo) ou uma expressão material do próprio Deus (panteísmo), mas não algo diverso, um outro, como polo de relação. Só um Deus pessoal pode ter diante de si um outro diferente. Mas Ele não cria esse outro para ter alguém com quem se comunicar, porque, do contrário, a criação seria uma necessidade imperiosa para Deus. A criação é um dom pessoal e livre de Deus a uma alteridade, mas não como se necessitasse desse outro, porque Deus já tem o seu Outro eterno e necessário, as pessoas da Trindade. Se a criação fosse essencial para a comunicação de Deus, não se poderia distinguir entre Criador e criatura e Deus não seria livre na sua autocomunicação amorosa.

Rev. Pistis Prax., Teol. Pastor., Curitiba, v. 1, n. 2, p. 355-369, jul./dez. 2009 
Essa perspectiva aparece no prólogo do Evangelho de João (Jo 1, 15) que é uma espécie de reinterpretação da criação do início do Gênesis (Gn 1,1 - 2,4). Existe um claro paralelismo. Os termos de conexão entre os dois textos são: palavra, vida, luz e trevas.

Para João, no início existia a Palavra que era Deus e estava voltada para Deus como comunicação interna ao nível da Trindade. Tudo foi criado por esta Palavra e sem ela nada foi feito. A Palavra comunica-se "ad extra”. A vida estava na Palavra e se comunicou aos seres humanos por meio dela na força do Espírito. Esta vida é luz para os seres humanos que vence as trevas. A Palavra era a verdadeira luz que, vindo ao mundo, ilumina a todo ser humano pelo Espírito. A comunicação “ad extra” na criação é possibilitada pela comunicação "ad intra" na Trindade.

O Gênesis afirma que no início existiam as trevas do abismo, o espírito ou o sopro de Deus (a palavra interna) pairava sobre as águas e Deus disse (palavra expressa): "Faça-se a luz e a luz foi feita”. As diferentes criaturas vão surgindo no decorrer dos dias da semana pela palavra de Deus como uma autocomunicação amorosa, porque tudo foi criado na bondade.

Essa fundamentação trinitária exige uma visão cristológica e pneumatológica da criação e uma intercompenetração compreensiva entre a protologia (conhecimento sobre a origem do mundo na criação inicial) e a escatologia (conhecimento sobre a consumação do mundo na nova criação). O que significa dizer que tudo foi criado por Cristo e no Espírito Santo? (MOLTMANN, 1993)

\section{Nova criação e criação contínua}

A criação inicial não deu origem a um sistema fechado e acabado, como se Deus tivesse que apenas conservar o que foi criado. Deus pôs em movimento a criação para que evolua em direção a novas possibilidades. A criação está aberta à história que pode acarretar corrupção e salvação, aniquilação e consumação. Deus suscitou a criação para que fosse o reino de sua glória e a mantém nessa direção. Assim a criação é desde o início um sistema aberto que não tem em si mesmo o seu fundamento, sua meta e seu equilíbrio. Caminha em direção à nova criação. Desde o início ela tem uma referência excêntrica alinhada em direção ao futuro. Sendo um sistema aberto torna possível uma 
história de corrupção, salvação e consumação. Por isso a meta da criação não é o retorno ao estado paradisíaco da origem, mas a revelação da glória de Deus na nova criação. Não é possível uma compreensão cristã da criação inicial sem referência à criação contínua e à nova criação.

A criação contínua compreende tanto a conservação do mundo, quanto a sua preparação para a consumação. Não se pode reduzir a atividade criadora de Deus ao início e falar historicamente apenas de conservação e escatologicamente apenas de redenção. O verbo criar referido a Deus está mais ligado à atividade criadora de Deus na história do que a atividade inicial. A criação na história é um criar a partir do que já foi criado. Pode ter um caráter de conservação diante dos poderes de aniquilação. Deus cria de forma continuada o já criado, dá um “sim” permanente à criação. Realiza a criação, sustentando e conservando. Mas não se pode reduzir a ação criadora de Deus a essa dimensão. Os profetas apontam para uma atividade criadora que suscita o novo e não apenas conserva. Abre possibilidades novas que antecipam a salvação. Tratase de uma criação nova que antecipa e prepara a consumação final.

A criação inicial foi sem esforço e resistência para Deus, porque dependia apenas de sua palavra. A criação contínua na história exige empenho, porque o Criador sofre as contradições da suas criaturas. Tolera os desvios e carrega os pecados e enfermidades das criaturas sobre o servo de Deus (Is 53,5). A criação salvífica brota do sofrimento. A criação da nova justiça brota do padecimento da injustiça. A criação de Deus na história acarreta paixão e ação e não só palavra como no início. A força criadora de Deus na história vem da inesgotabilidade de sua capacidade de sofrimento. Isto não é sinal de debilidade, mas revelação da fortaleza do seu amor. A paciência infinita do criador e a sua ativa capacidade de sofrimento é a raiz da atividade criadora de Deus na história. A força transformadora do sofrimento constitui a base da atuação libertadora e consumadora de Deus. Realiza essa atividade pela força do Espírito, pois toda criatura está inundada pelo sopro do Espírito.

A criação contínua na história é atuada pela presença do Espírito no sentido de conservar e preparar o mundo para a nova criação. O Espírito recolhe os gemidos das criaturas ansiosas pela libertação e atualiza as possibilidades que antecipam a consumação final. Assim, toda criação exala o sopro vivificador do Espírito, conduzindo as criaturas à sua meta de plenitude, quando Deus será tudo em todos e não haverá injustiça e desgraça, porque despontará a nova justiça, antecipada pela proclamação do Reino. Portanto, 
JUNGES, J. R.

não tem sentido para a fé tentar compreender cosmologicamente o surgimento do mundo, porque a criação inicial surge em previsão da nova criação que é a sua meta, passando pela criação contínua que acontece na historia a partir da força da ressurreição de Cristo e pela ação do Espírito. Ciência e fé não podem colidir, porque falam a partir de pontos de vista totalmente diversos: a primeira tem uma perspectiva cosmológica e a segunda, escatológica (MOLTMANN, 1993; FERRETI, 2000).

\section{Criação de céu e terra}

O relato do Gênesis inicia com a frase: No princípio Deus criou o céu e a terra.... ${ }^{1} \mathrm{O}$ ato de "criar" é exclusivo do tempo inicial, seguido depois pela ação ordenadora dos diferentes dias, onde não aparece o verbo "criar”, mas “fazer”. O que é criado é “o céu e a terra”. Céu se refere ao de cima, fora do alcance humano e indisponível, ao inacessível e desconhecido. Terra compreende o de baixo, que está ao alcance do ser humano e lhe é familiar. Terra é também o espaço vital dos seres vivos, oposto ao céu que é o mundo dos anjos e de Deus. Qual é o sentido deste binômio de oposição, que aparece em vários lugares da Escritura (Dt 10, 14; 1 Rs 8, 27; Ne 9, 6)?

O que é o “céu”? Não pode significar o lugar de habitação de Deus, porque onde estava Deus antes de criar o céu, nem o firmamento celeste, porque este foi feito no segundo dia. Por que um mundo dual?

O binômio inicial de “céu e terra” (MOLTMANN, 1993, p. 235-270) está numa analogia com Criador e criatura. Céu é desde donde Deus atua e onde se realiza plenamente a sua vontade. Rezamos que se faça a sua vontade assim na terra como no céu. A terra é para onde se orienta a ação amorosa e criadora de Deus. O binômio “céu e terra” serve para designar um mundo aberto à influência de Deus. O mundo não gira sobre si mesmo, mas existe na presença e sob a influência constante do Criador. Com o termo "Céu” designa-se a face da criação aberta a Deus. Por isso se pode falar de “céus” no plural, porque os

1 A tradução conhecida como Bíblia de Jerusalém (1980, p. 31) prefere seguir esta antiga versão, porque respeita melhor a coerência do texto e tradicionalmente é a mais conhecida. Na Tradução Ecumênica da Bíblia (1994, p. 24) aparece a versão "No princípio, quando Deus criou o céu e a terra..."

Rev. Pistis Prax., Teol. Pastor., Curitiba, v. 1, n. 2, p. 355-369, jul./dez. 2009 
céus significam para a terra o reino das possibilidades criadoras de Deus. Céu é a transcendência relativa da terra e esta é imanência relativa do céu. Um mundo sem céu seria um mundo fechado sobre si mesmo. Um mundo sem transcendência é um mundo em que nada de novo pode acontecer. É o eterno retorno. Sem céu não existe criação contínua. Céu e terra são as duas caras da atividade de Deus.

Céu é o reino das energias, das possibilidades e da potência de Deus. Desde este céu, Deus ordena o céu como firmamento e a terra. Desde o céu significa desde o movimento criador de Deus. Terra designa a realidade cognoscível, determinável e acessível ao ser humano. Céu designa para a terra o inabarcável e incomensurável, mas possibilidade determinante para a terra. Céu é o reino das possibilidades criadoras de Deus para a terra. Elas têm prioridade sobre a realidade empírica do mundo e as próprias possibilidades inerentes a ela. Em comparação com a realidade caduca do mundo, o céu é imperecível, mas em comparação com Deus é finito, porque foi criado como conjunto de possibilidades para a terra. Estas possibilidades não se esgotam em sua realização.

Céu designa o reino dos poderes de Deus e as potencialidades para o ser da terra desenvolver-se numa criação continua. Sendo o mundo uma realidade aberta à criação contínua, é necessário um conjunto de possibilidades utópicas criadas por Deus e designadas como céu que servem de modelo e impulso. Estas possibilidades e potencialidades para a terra não são algo do ser eterno de Deus, mas enquanto ser criador de um mundo distinto dele, mas em comunicação. Neste sentido, céu é o primeiro mundo que Deus criou para configurar a terra. Por isso, os Santos Padres puderam ver neste céu o mundo das ideias de Platão como lugar dos arquétipos das coisas criadas.

Cristo abriu para a humanidade e toda a criação as portas do céu. Ele anunciou o Reino dos céus. Assim, céu da graça designa as potencialidades da nova criação. O céu estava fechado por causa da caída original e a humanidade encontrava-se sob o juízo de Deus. Céu aberto, ao contrário, é o tempo da graça. Significa que Deus volta seu rosto para a humanidade, acontecendo a redenção e que a terra recupera a sua fertilidade, irrompendo a nova criação (Mt 3, 16; Lc 10, 18; At 7, 55; Ef 1, 20s).

Portanto, céu é uma categoria central da compreensão cristã da criação, como conjunto de possibilidades criadas em vista da criação contínua e como expressão da nova criação. Na tradição, o céu foi divinizado, elevando-o 
JUNGES, J. R.

à transcendência da incriada majestade de Deus e identificando-o com o próprio Deus. A terra, por outro lado, foi entregue a total imanência e acessibilidade do ser humano com todas as consequências de domínio e exploração. Céu e terra tornaram-se realidades antagônicas e opostas. Se a terra tivesse permanecido aberta às possibilidades criadoras que vem de Deus, simbolizadas pelo céu, o ser humano teria respeitado a natureza.

\section{O sábado da criação}

É necessário deixar claro que o contexto bíblico da criação é teocêntrico e não antropocêntrico. O relato criacional não está centrado no ser humano, mas na ação criadora de Deus. Nesse sentido o texto bíblico não termina no surgimento do ser humano como sempre se pensa, mas no descanso sabático de Deus (MOLTMANN, 1993). O repouso de Deus é a volta a si depois de ter saído de si para criar. Deus se autolimitou ao sair de si e criar algo diferente de si. Abriu um espaço onde fosse possível o aparecimento das criaturas. Mas esse espaço está em Deus e, por isso, ao descansar e voltar a si, Deus traz consigo todas as criaturas. Nesse sentido elas também descansam em Deus. Não só Deus descansa das criaturas, porque volta a si, mas elas repousam diante do olhar pacificador de Deus, porque encontram proteção diante da fragilidade de sua vida que as pode novamente reduzir a nada.

A compreensão do descanso sabático de Deus foi reduzido a fundamento de prescrições religiosas, perdendo seu significado para a compreensão da criação. As criaturas na sua fragilidade encontram em Deus o seu repouso diante da contínua ameaça de aniquilação. Por isso elas descansam em Deus que as mantém em vida. O ser humano é também uma ameaça para elas. O descanso sabático recorda continuamente que os seres vivos são criaturas de Deus e não simples objetos de manipulação a serviço de interesses humanos. A rotina do trabalho de intervenção na natureza é interrompida pelo dia do sábado ou pelo ano sabático para lembrar o ser humano que a natureza é criação de Deus. A natureza é deixada descansar, o ser humano não intervém pelo seu trabalho para que ela recupere seu ritmo e repouse em sua harmonia. $\mathrm{O}$ afã de lucro do capitalismo significou uma gradativa anulação dos dias de descanso, reduzindo a natureza à mercadoria, negando sua condição de criação de Deus.

Rev. Pistis Prax., Teol. Pastor., Curitiba, v. 1, n. 2, p. 355-369, jul./dez. 2009 


\section{Papel do ser humano na criação}

Outro aspecto da doutrina bíblica da criação com incidência na questão ecológica é a afirmação de que o ser humano foi criado à imagem e semelhança divina (GESCHÉ, 1991; REIJNEN, 2000). Essa afirmação sempre foi usada para defender a precedência e o protagonismo do ser humano no conspecto da criação. Sem dúvida é afirmada a posição privilegiada na escala dos outros seres vivos. A questão é o significado desse lugar especial. Em que o ser humano é feito à imagem e semelhança divina? Certamente não no senhorio absoluto de Deus. Ele não é senhor, mas um puro administrador da criação que lhe é entregue por Deus em cuidado. Deus criou o ser humano como seu interlocutor entre as criaturas. Por isso foi criado à imagem do Filho para que espelhasse o rosto do Filho, sendo assim o representante de Deus diante da Criação e o representante das criaturas diante de Deus. A imagem divina do ser humano está ao serviço dessa representação. O conteúdo da sua semelhança com Filho é o papel de mediador entre Deus e as criaturas. Trata-se de uma representação subsidiária de Deus na linha da criação e do descanso das criaturas em Deus. O papel do ser humano não é apropriar-se da natureza como dono e explorador, mas realizar a função de um jardineiro que cuida da harmonia e beleza do jardim criado por Deus. Portanto, a representação deve ser exercida na perspectiva do cuidado.

A compreensão do significado, para a criação, do descanso sabático de Deus e da representação subsidiária do ser humano leva a interpretar de outro modo o que foi tradicionalmente traduzido em Gn 1, 28 por "dominai a terra" e "submetei dos animais". Não se trata de dominar e submeter no sentido de subjugar e oprimir, porque isto seria a negação do senhorio de Deus. Em relação à terra, o ser humano é convidado a ocupá-la para seu sustento. A terra está a serviço da reprodução da vida e a sua ocupação é para tirar dela o alimento.

Em relação aos animais, o ser humano é convidado a ser um juiz de paz na linha de Is 11, 6-9. Esse texto apregoa a harmonia vegetariana entre os animais, já que no relato da criação só a erva é dada como alimento a todo ser vivo (Gn 1, 29-30). A licença para comer carne só virá depois do pecado e do dilúvio, embora fique a proibição de consumir carne com vida, isto é, com seu sangue (Gn 9, 3-4). O fato do ser humano dar nome aos animais (Gn 2, 19c-20) tem o sentido de introduzi-los na comunidade linguística humana, considerandoos como parceiros de ajuda (Gn 2, 18) e de sorte $(\mathrm{Ecl} 3,19)$. Portanto, não se trata de submissão, mas parceria.

Rev. Pistis Prax., Teol. Pastor., Curitiba, v. 1, n. 2, p. 355-369, jul./dez. 2009 


\section{Conclusão}

O desafio ecológico obriga o cristianismo voltar às origens semitas da compreensão bíblica da criação, possibilitando o resgate teológico de aspectos da natureza que estavam esquecidos devido a uma visão cosmológica e epistemológica própria da ciência moderna que serviu de princípio hermenêutico para a explicação do texto bíblico. Essa sim é a responsável pela crise ambiental e usou a bíblia ao seu favor. Só assim se poderá responder com propriedade à acusação injustificada de que a doutrina cristã da criação, presente no gênesis, provocou a destruição da natureza. Para isso é necessário desconstruir determinada interpretação que se disseminou e está impropriamente na mente de muitos cristãos.

\section{Referências}

A BÍBLIA DE JERUSALÉM, São Paulo: Paulinas, 1980.

EUVÉ, F. Pensar a criação como jogo. São Paulo: Paulinas, 2006.

FERRETTI, C. T. Creazione continua: il futuro e la crazione. Rassegna di Teologia, Napoli, v. 41, n. 2, p. 223-259, 2000.

GESCHÉ, A. L'homme créé créateur. Revue Théologique de Louvain, Paris, v. 22, n. 2, p. 153-184, 1991.

MOLTMANN, J. Deus na criação: doutrina ecológica da criação. Petrópolis: Vozes, 1993.

MONCRIEF, L. W. The cultural base for our environmental crisis. Science, v. 170, n. 3957, p. 508-512, 1970.

REIJNEN A. M. Maître ou parasite? habiter la nature en toute conscience. Revue Théologique de Louvain, Paris, v. 32, n. 2, p. 169-189, 2000.

RICOEUR, P. La Métaphore vive. Paris: Seuil, 1975. 
VIVES, J. Trinidad, creación y liberación. Revista Latinoamericana de Teología, San Salvador, v. 7, n. 19, p. 41-67, 1990.

WHITE, J. R. L. Historical roots of our ecologic crisis. Science, v. 155, n. 3767, p. 1203-1207, 1967.

Recebido: 01/11/2008

Receveid: 11/01/2008

Aprovado 02/05/2009

Approved: 05/02/2009

Revisado: 16/07/2009

Reviewed: 07/16/2009 